\title{
A Lebanese family with autosomal recessive oculo-auriculo-vertebral (OAV) spectrum and review of the literature: is OAV a genetically heterogeneous disorder?
}

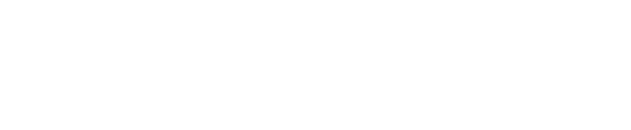

\section{Chantal Farra ${ }^{1,2}$ \\ Khaled Yunis' \\ Nadine Yazbeck' \\ Marianne Majdalani' \\ Lama Charafeddine' \\ Rima Wakim' \\ Johnny Awwad ${ }^{3}$}

'Department of Pediatrics and Adolescent Medicine, ${ }^{2}$ Department of Pathology, ${ }^{3}$ Department of

Obstetrics and Gynecology, American University of Beirut Medical Center, Beirut, Lebanon
Correspondence: Johnny Awwad Department of Obstetrics and Gynecology, American University of Beirut Medical Center, PO Box I I-0236, Riad El Solh, I 107 2020, Beirut, Lebanon

Tel +96 I l 353465, ext 5500

Fax+96 | | 37038 I

Email jawwad@aub.edu.lb
Abstract: Oculo-auriculo-vertebral (OAV) spectrum summarizes a continuum of ocular, auricular, and vertebral anomalies. Goldenhar syndrome is a variant of this spectrum and is characterized by pre-auricular skin tags, microtia, facial asymmetry, ocular abnormalities, and vertebral anomalies of different sizes and shapes. Most cases are thought to be sporadic. However, a few families were reported to have an autosomal recessive inheritance and other families' presentation of the syndrome strongly supported an autosomal dominant inheritance. We report OAV in a female infant presenting with tracheomalacia, diaphragmatic hernia, encephalomeningocele, sacral neural tube defect, and cardiac defect and her brother having no more than dysmorphic features. The mode of inheritance in this family supports an autosomal recessive inheritance where the transmission was from normal first-degree consanguineous parents to one of the sons and to the daughter. This report further broadens the clinical presentation and symptoms of OAV and supports the hypothesis advancing OAV as a genetically heterogeneous disorder.

Keywords: oculo-auriculo-vertebral spectrum, Goldenhar syndrome, diaphragmatic hernia, neural tube defect

\section{Introduction}

Goldenhar syndrome was first described in 1952 in three patients with epibulbar dermoids, pre-auricular skin tags, mandibular asymmetry and cervical vertebrae abnormalities. ${ }^{1}$ Later on, Gorlin et al reported similar findings for which they suggested the term oculo-auriculo-vertebral (OAV) dysplasia, which was then changed to oculoauriculovertebral (OAV) spectrum by Cohen et al., Currently, the term OAV summarizes a continuum of ocular, auricular, and vertebral anomalies that were described previously in Goldenhar syndrome, hemifacial microsomia as well as first and second branchial arch anomalies. ${ }^{2,4-6}$ The clinical presentation can be mild or severe. The incidence of OAV has been estimated at $1 / 3500,{ }^{7} 1 / 5600,{ }^{2,8,9}$ and $1 / 26,550$ live births. ${ }^{10}$

Most cases are thought to be sporadic; however, a few families were reported to have an autosomal recessive inheritance. ${ }^{11-18}$ Other families' presentation of the syndrome strongly supported an autosomal dominant inheritance. ${ }^{6,8,19-27}$

We describe OAV in a female infant and in her brother. In this family, we report an autosomal recessive transmission from normal first-degree consanguineous parents to 
one of the sons and to the daughter, both of which presented with OAV but with variable genetic expression. This case report broadens the clinical presentation and symptoms of OAV and supports the hypothesis advancing OAV as a genetically heterogeneous disorder.

\section{Case report}

The proband was a full-term female infant born at $37+3$ weeks of gestation (birth weight: $3045 \mathrm{~g}$ ) to a 27-year-old healthy woman (G3P3SAb0) by cesarean section for fetal distress. Apgar scores at 1 and 5 minutes were 8 and 8 , respectively. Maternal antenatal history was clear for any medication intake, alcohol ingestion, or drug usage. The proband had two older brothers born to firstdegree consanguineous parents of Lebanese Middle East ascendants. The first, a 6-year-old, was diagnosed with OAV. He reportedly was noticed at birth to have right microtia, right mandibular hypoplasia, and two anterior left ear skin tags with no other anomalies. He was operated on for ear malformations but still has growth delay.

The second child was found to be developmentally normal with no detectable malformations. Family history revealed two interrupted pregnancies from the paternal side from equally consanguineous parents (Figure 1).

At birth, the proband developed tachypnea and was transferred to the Neonatal Intensive Care Unit (NICU). Blood gases and $\mathrm{O}_{2}$ saturation were stable. Physical examination was remarkable for the following findings: short neck, widely spaced nipples, dysmorphic features including hypertelorism, upslanting palpebral fissures, flat nasal bridge, right mandibular hypoplasia, and facial asymmetry more obvious when the newborn cried. Her ears were normal-looking except for one preauricular left ear skin tag.

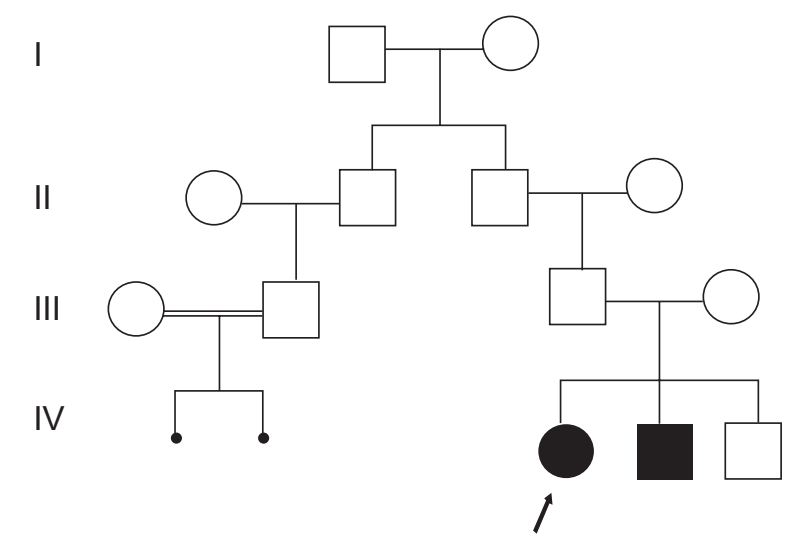

Figure I The pedigree shows two interrupted pregnancies from the paternal side from equally consanguineous parents.
Soon, the respiratory condition of the newborn deteriorated, necessitating the placement of continuous positive airway pressure with the presumptive diagnosis of pneumonia. On day 5, a CT scan of chest revealed right diaphragmatic hernia with two-thirds of the liver protruding into the right chest and lower lobe consolidation. CT scan of brain and neck showed occipital encephalomeningocele. Echocardiography detected moderate perimembraneous ventricular septal defect, sinus venous arterial septal defect, and mild pulmonary hypertension. There was no evidence of congestive heart failure. Diuretic management with furosemide and spironolactone was started.

On day 16, she underwent an uneventful surgical repair of diaphragmatic hernia.

On day 24, surgical correction of the encephalomeningocele was performed with no intra-operative complications.

At 5 months of age, the infant suffered profound oxygen desaturation and bradycardia followed by cardiac arrest. Cardiopulmonary resuscitation was initiated with no pick-up. The infant was declared dead following a flat ECG.

The cytogenetic studies consisted of conventional karyotyping using G-banding, which revealed a 46, XX normal female profile. Molecular analysis using fluorescence in situ hybridization (FISH) with the N25 and TUPLE 1 probes in the DGS/VCFS region at 22q11.2 revealed disomy for this locus, excluding any deletions in this particular region. Although array-CGH would be useful, it is unfortunately not possible in this case.

\section{Discussion}

OAV spectrum is characterized by pre-auricular skin tags, microtia, facial asymmetry, ocular abnormalities, and vertebral anomalies of different sizes and shapes.

Our female patient presented with facial asymmetry, diaphragmatic hernia, encephalomeningocele, and preauricular skin tag. On the other hand her sibling had facial asymmetry and abnormal ears. Although the siblings may have different conditions, they both have the phenotypic clinical features of OAV and fit the minimal criteria for OAV diagnosis. This variability attests to the wide phenotypic range and severity of OAV and supports the hypothesis advancing OAV as a genetically heterogeneous disorder.

There is no national register of congenital disorders in Lebanon to date. To the best of our knowledge, this is the second case of OAV reported from Lebanon. We have previously reported a case of OAV in a male infant born to a woman with a history of prenatal fluoxetine 
ingestion throughout her pregnancy. The infant was born from nonconsanguinous parents and had facial asymmetry with right microtia and mandibular hypoplasia; bilateral hypoplastic macula, scoliotic deformity of the thoracic spine; and ventricular septal defect. ${ }^{28}$

Cardiovascular anomalies have also been associated with OAV. ${ }^{29-34}$ The frequency of cardiovascular heart defects in OAV ranged from 5\% to $58 \%$ with conotruncal defects and septal defects as the most common among patients, as it was manifested in our patient. ${ }^{33,34}$

Of important note is that our patient also presented with diaphragmatic hernia that was repaired surgically. Congenital diaphragmatic hernias, as well as encephalocele, have been associated previously with Goldenhar syndrome. ${ }^{25,35}$

The clinical presentation of OAV varies among patients. Stoll et al reported OAV in a mother and two of her children. The mother had only auricular anomalies. Her first child, a female, presented with many anomalies including: bilateral cleft lip and palate, a coloboma of the upper eyelid, facial asymmetry, and posteriorly angulated ears. Her second child, a male, presented with cleft lip and palate, clubfeet, hypoplasia of the left ear and of the left maxillary and mandibular arches, and left microphthalmia. ${ }^{25}$

Symptoms of OAV were also described in two infants (a male and a female) who also shared features of the CHARGE association. Each had facial asymmetry, mandibular hypoplasia, ear abnormalities, hearing impairment, microphthalmia, heart defects, and developmental delay. In addition, both had plagiocephaly and torticollis and the boy presented with cleft lip, heminostril, and tracheoesophageal fistula. ${ }^{36}$ Later on, studies revealed a variety of symptoms in addition to the general characteristics of the OAV such as dysplastic ectopic, or bilobed caruncles, nasal sinus, nasal-ocular cleft, ${ }^{37}$ ocular colobomas, ${ }^{38}$ facial nerve paralysis and mental retardation, ${ }^{39}$ speech impairment, and difficulties in feeding/eating. ${ }^{40}$ Growth hormone deficiency was also reported in a patient with OAV but no association was proved. ${ }^{41}$

Most cases of OAV reported are sporadic but familial cases have been described. Kaye et al rejected the hypothesis of no genetic transmission and reported an autosomal dominant inheritance after examining families of 74 probands. ${ }^{5}$ In 1963, Saraux et al described the condition in two sisters born of healthy unrelated parents with normal karyotype, as reported in our case. ${ }^{11}$ Three years later, the same condition was reported in a son and daughter to consanguineous parents where the father was also affected. ${ }^{12}$ Recently, Tasse et al described the transmission of OAV from a mother to her daughter. ${ }^{6}$ The mode of inheritance was autosomal dominant. Tasse et al also concluded after reviewing the literature that patients with autosomal dominant inheritance of OAV present more often with bilateral anomalies. ${ }^{6}$

Amalnath et al described OAV in three brothers. The authors suggested that the occurrence of this condition in all three male siblings and its absence in the parents suggests an $\mathrm{X}$-linked mode of inheritance in the family. ${ }^{42}$

On the other hand, Ellwood et al reported an autosomal recessive transmission in an Arabic family presenting with bilateral anotia and meatal atresia and in a Jewish family presenting with unilateral microtia and meatal atresia. ${ }^{13}$ Strisciuglio et al postulated a recessive inheritance in a sibship with a wide variation of expression. ${ }^{43}$ The family that was described had two brothers presenting with unilateral right microtia and bilateral meatal atresia. The sister presented with preauricular left appendage with absence of other anomalies. The absence of any ear anomalies in the parents suggested an autosomal recessive inheritance. ${ }^{43}$ The difference in severity of the clinical presentation in the children reveals a high variation in the manifestations in this syndrome. The above mentioned studies further elucidate the role of an autosomal recessive inheritance.

Different reports have described OAV along with different cytogenetic findings. OAV has been reported in a patient with complete trisomy $22,{ }^{44}$ also in a male infant who had also the cri-du-chat syndrome and was found to have, upon cytogenic examination, a deletion of chromosome $5 \mathrm{p} 14 .{ }^{45}$ Descartes reported an association of Goldenhar syndrome in a patient with a 5pter-p15.33 deletion. ${ }^{46}$ Ala-Mello et al reported a complex translocation resulting in a deletion of 5pter-p15.3, deletion of 21q22.3-qter, and duplication of 21q22.11-q22.12 in a patient presenting with features of Goldenhar syndrome and hematologic anomalies. ${ }^{47}$ However, our patient had a normal karyotype.

Our patient had a brother who was diagnosed with OAV with asymmetrical face and abnormal ears. However, the brother's clinical symptoms varied from the reported patient and the degree of severity was mild. The parents did not present any abnormalities nor did the third sibling. The mode of inheritance in this family supports an autosomal recessive inheritance.

In conclusion, this case report further broadens the clinical presentation and symptoms of OAV and supports the hypothesis advancing OAV as a genetically heterogeneous disorder. While the corresponding genetic defect underlying OAV remains poorly understood, this report could at some 
point prove to be useful in improving our understanding of the disorder and its underlying genetic mechanisms.

\section{Disclosure}

The authors declare no conflicts of interest.

\section{References}

1. Goldenhar M. Associations malformatives do l'oeil et de l'oreille, en particulier le syndrome dermoïde epibulbaire-appendices auriculairesfistula auris congenita et ses relations avec la dysostose mandibulofaciale. J Genet Hum. 1952;1:243-282. French.

2. Gorlin RJ, Jue KL, Jacobsen U, Goldschmidt E. Oculoauriculovertebral dysplasia. J Pediatr. 1963;63:991-999.

3. Cohen MM Jr, Rollnick BR, Kaye CI. Oculoauriculovertebral spectrum: an updated critique. Cleft Palate J. 1989;26(4):276-286.

4. Rollnick BR, Kaye CI, Nagatoshi K, Hauck W, Martin AO. Oculoauriculovertebral dysplasia and variants: phenotypic characteristics of 294 patients. Am J Med Genet. 1987;26(2):361-375.

5. Kaye CI, Martin AO, Rollnick BR, et al. Oculoauriculovertebral anomaly: segregation analysis. Am J Med Genet. 1992;43(6):913-917.

6. Tasse C, Majewski F, Bohringer S, et al. A family with autosomal dominant oculo-auriculo-vertebral spectrum. Clin Dysmorphol. 2007; 16(1):1-7.

7. Poswillo D. Otomandibular deformity: pathogenesis as a guide to reconstruction. J Maxillofac Surg. 1974;2(2-3):64-72.

8. Grabb WC. The first and second branchial arch syndrome. Plast Reconstr Surg. 1965;36(5):485-508.

9. Hartsfield JK. Review of the etiologic heterogeneity of the oculoauriculo-vertebral spectrum (Hemifacial Microsomia). Orthod Craniofac Res. 2007;10(3):121-128.

10. Melnick M. The etiology of external ear malformations and its relation to abnormalities of the middle ear, inner ear, and other organ systems. Birth Defects: Original Article Series. 1980;16(4):303-331.

11. Saraux H, Grignon JL, Dhermy P. A propos d'une observation familiale de syndrome de Franceschetti-Goldenhar. Bull Soc Ophtal Franc. 1963;63:705-707. French.

12. Proto F, Scullica L. Contributo allo studio della ereditarieta dei dermoidi epibulbari. Acta Genet Med Gemellol. 1966;15:351-363. Italian.

13. Ellwood LC, Winter ST, Dar H. Familial microtia with meatal atresia in two sibships. J Med Genet. 1968;5(4):289-291.

14. Kirke DK. Goldenhar's syndrome: two cases of oculo-auriculo-vertebral dysplasia occurring in full-blood Australian aboriginal sisters. Aust Paediatr J. 1970;6(4):213-214.

15. Krause U. The syndrome of goldenhar affecting two siblings. Acta Ophthalmol. 1970;48(3):494-499.

16. Konigsmark BW, Nager GT, Haskins HL. Recessive microtia, meatal atresia, and hearing loss. Report of a sibship. Arch Otolaryngol. 1972; 96(2):105-109.

17. Schmid M, Schroder M, Langenbeck U. Familial microtia, meatal atresia, and conductive deafness in three siblings. Am J Med Genet. 1985;22(2):327-332.

18. Witters I, Schreurs J, Van Wing J, Wouters W, Fryns JP. Prenatal diagnosis of facial clefting as part of the oculo-auriculo-vertebral spectrum. Prenat Diagn. 2001;21(1):62-64.

19. Summitt RL. Familial Goldenhar syndrome. Birth Defects. 1969;5: 106-109.

20. Parving A. Progressive hearing loss in Goldenhar's syndrome. Scand Audiol. 1978;7(2):101-103.

21. Setzer ES, Ruiz-Castaneda N, Severn C, Ryden S, Frias JL. Etiologic heterogeneity in the oculoauriculovertebral syndrome. J Pediatr. 1981;98(1):88-90.

22. Regenbogen L, Godel V, Goya V, Goodman RM. Further evidence for an autosomal dominant form of oculoauriculovertebral dysplasia. Clin Genet. 1982;21(3):161-167.
23. Rollnick BR, Kaye CI. Hemifacial microsomia and variants: pedigree data. Am J Med Genet. 1983;15(2):233-253.

24. Singer SL, Haan E, Slee J, Goldblatt J. Familial hemifacial microsomia due to autosomal dominant inheritance. Case reports. Aust Dent J. 1994;39(5):287-291.

25. Stoll C, Viville B, Treisser A, Gasser B. A family with dominant oculoauriculovertebral spectrum. Am J Med Genet. 1998;78(4): 345-349.

26. Tasse C, Bohringer S, Fischer S, et al. Oculo-auriculo-vertebral spectrum (OAVS): clinical evaluation and severity scoring of 53 patients and proposal for a new classification. Eur J Med Genet. 2005;48(4):397-411.

27. Vendramini-Pittoli S, Kokitsu-Nakata NM. Oculoauriculovertebral spectrum: report of nine familial cases with evidence of autosomal dominant inheritance and review of the literature. Clin Dysmorphol. 2009;18(2):67-77.

28. Farra C, Yunis K, Mikati M, Yazbeck N, Majdalani M, Awwad J. Goldenhar syndrome associated with prenatal maternal Fluoxetine ingestion: Cause or coincidence? Birth Defects Res A Clin Mol Teratol. 2010;88(7):582-585.

29. Kumar A, Friedman JM, Taylor GP, Patterson MW. Pattern of cardiac malformation in oculoauriculovertebral spectrum. Am J Med Genet. 1993;46(4):423-426.

30. van Bever Y, van den Ende JJ, Richieri-Costa A. Oculo-auriculovertebral complex and uncommon associated anomalies: report on 8 unrelated Brazilian patients. Am J Med Genet. 1992;44(5):683-690.

31. Lin HJ, Owens TR, Sinow RM, et al. Anomalous inferior and superior venae cavae with oculoauriculovertebral defect: review of Goldenhar complex and malformations of left-right asymmetry. Am J Med Genet. 1998;75(1):88-94.

32. Derbent M, Orun UA, Varan B, et al. A new syndrome within the oculo-auriculo-vertebral spectrum: microtia, atresia of the external auditory canal, vertebral anomaly, and complex cardiac defects. Clin Dysmorphol. 2005;14(1):27-30.

33. Morrison PJ, Mulholland HC, Craig BG, Nevin NC. Cardiovascular abnormalities in the oculo-auriculo-vertebral spectrum (Goldenhar syndrome). Am J Med Genet. 1992;44(4):425-428.

34. Digilio MC, Calzolari F, Capolino R, et al. Congenital heart defects in patients with oculo-auriculo-vertebral spectrum (Goldenhar syndrome). Am J Med Genet A. 2008;146A(14):1815-1819.

35. Kita D, Munemoto S, Ueno Y, Fukuda A. Goldenhar's syndrome associated with occipital meningoencephalocele--case report. Neurol Med Chir (Tokyo). 2002;42(8):354-355.

36. Van Meter TD, Weaver DD. Oculo-auriculo-vertebral spectrum and the CHARGE association: clinical evidence for a common pathogenetic mechanism. Clin Dysmorphol. 1996;5(3):187-196.

37. Nijhawan N, Morad Y, Seigel-Bartelt J, Levin AV. Caruncle abnormalities in the oculo-auriculo-vertebral spectrum. Am J Med Genet. 2002;113(4):320-325.

38. Beck AE, Hudgins L, Hoyme HE. Autosomal dominant microtia and ocular coloboma: new syndrome or an extension of the oculo-auriculovertebral spectrum? Am J Med Genet A. 2005;134(4):359-362.

39. Touliatou V, Fryssira H, Mavrou A, Kanavakis E, Kitsiou-Tzeli S. Clinical manifestations in 17 Greek patients with Goldenhar syndrome. Genet Couns. 2006;17(3):359-370.

40. Stromland K, Miller M, Sjogreen L, et al. Oculo-auriculo-vertebral spectrum: associated anomalies, functional deficits and possible developmental risk factors. Am J Med Genet A. 2007;143A(12):1317-1325.

41. Yusufoglu AM, Cetinkaya E, Ceylaner S, et al. Goldenhar syndrome associated with growth hormone deficiency. Genet Couns. 2008;19(2):173-176.

42. Amalnath SD, Subrahmanyam DK, Dutta TK, Shenoy P. Familial oculoauriculovertebral sequence with lymphoma in one sibling. Am J Med Genet A. 2008;146A(23):3082-3085.

43. Strisciuglio P, Ballabio A, Parenti G. Microtia with meatal atresia and conductive deafness: mild and severe manifestations within the same sibship. J Med Genet. 1986;23(5):459-460. 
44. Kobrynski L, Chitayat D, Zahed L, et al. Trisomy 22 and facioauriculovertebral (Goldenhar) sequence. Am J Med Genet. 1993;46(1):68-71.

45. Choong YF, Watts P, Little E, Beck L. Goldenhar and cri-du-chat syndromes: a contiguous gene deletion syndrome? J AAPOS 2003;7(3):226-227.

46. Descartes M. Oculoauriculovertebral spectrum with 5 p15.33-pter deletion. Clin Dysmorphol. 2006;15(3):153-154.
47. Ala-Mello S, Siggberg L, Knuutila S, von Koskull H, Taskinen M, Peippo M. Further evidence for a relationship between the $5 \mathrm{p} 15$ chromosome region and the oculoauriculovertebral anomaly. Am J Med Genet A. 2008;146A(19):2490-2494.

The Application of Clinical Genetics

\section{Publish your work in this journal}

The Application of Clinical Genetics is an international, peer-reviewed open access journal that welcomes laboratory and clinical findings in the field of human genetics. Specific topics include: Population genetics Functional genetics; Natural history of genetic disease; Managemen of genetic disease; Mechanisms of genetic disease; Counselling and ethical issues; Animal models; Pharmacogenetics; Prenatal diagnosis; Dysmorphology. The manuscript management system is completely online and includes a very quick and fair peer-review system, which is all easy to use. Visit http://www.dovepress.com/testimonials.php to read real quotes from published authors.

Submit your manuscript here: http://www.dovepress.com/the-application-of-clinical-genetics-journal 